\title{
Study on Loading-Machine Production Scheduling Algorithm of Forest-Pulp-Paper Enterprise
}

\author{
Guohua Zhang ${ }^{1}$, Xiang $\mathrm{Li}^{1}$, Yang Yang ${ }^{1} \&$ Minghuang Chen ${ }^{1}$ \\ ${ }^{1}$ Hunan University of Technology, China \\ Correspondence: Guohua Zhang, Hunan University of Technology, Zhuzhou, Hunan, 412000, China. E-mail: \\ 578422815@qq.com
}

Received: January 1, 2017

Accepted: February 23, 2017

Online Published: March 9, 2017

doi:10.5539/cis.v10n2p25

URL: http://doi.org/10.5539/cis.v10n2p25

\begin{abstract}
Aid program for Science and Technology Innovative Research Team in Higher Educational Instituions of Hunan Province;
\end{abstract}

Key Laboratory of Intelligent Information Perception and Processing Technology (Hunan Province);

Scientific Research Projects of Hunan Education Department in 2016.

\begin{abstract}
Through the needs of Loading-Machine storage scheduling in forestry-pulp-paper production logistics intelligent distribution system, analysis the Loading-Machine scheduling model of problems and improvement measures, put forward Loading-Machine intelligent production scheduling algorithm, based on ensuring the feasibility of scheduling, scheduling to rationalization, equalization, execute only, production process optimization, and realize the Loading-Machine intelligent production scheduling through the computer programming.
\end{abstract}

Keywords: forest-pulp-paper enterprise, production logistics, loading-machine,scheduling algorithm

\section{Introduction}

One of the most important problems in the production logistics intelligent distribution system of Forest-Pulp

-Paper enterprise is to carry out the Loading-Machine production scheduling. The main production of wood in the workshop is completed by the Loading-Machine, and the pulp package is mainly carried out by the stacker or forklift. Therefore, it is necessary to realize the automatic scheduling of the handling equipment, and to ensure the feasibility of scheduling, so as to realize the scientific management of the Loading-Machine. Scheduling problem is a typical combinatorial optimization problem, which is an important research field of CIMS (computer integrated manufacturing). To determine the storage strategy and location assignment rules provide a strong guarantee for the calculation of these transportation production.

At present, the loader management approach is the administrator of verbal work instruction or to an operator or from the storage list of operators according to their own preferences to decide what to do , operator can find the target position for timber; operation chaos, low efficiency, error rate is high, often allowing out

-trucks for transporting logs for a long time waiting. There are a lot of waste and unreasonable.

Therefore, how to realize the automatic scheduling of the loader work becomes a problem needs to be solved. Due to scheduling object is loader (a device needs operating security), according to the regulations, still need to operate on the loader, so instructions need to be sent to the loader operator.

The loader scheduling problem to solve is: how to according to the production plan, timber delivery order, inventory plan from various departments of the use of timber demand, the automatic generation of the loader operating instructions, how to assign tasks to different loading machine to carry out the instructions, how to deliver necessary wood when necessary loading machine, send work order at what moment, how to determine the operation order, how to ensure the mixed order can arranged well and deadlock phenomenon is not appear, how to according to the actual situation of change auto released work instructions, how to monitoring perform tasks, how to ensure wrong order don't be execution. 


\section{Overview of Loading-Machine Scheduling Problem}

\subsection{Description of Scheduling Problem}

Regarded the wood or wood chip as a workpiece, regarded the loader as a special processing of wood, each of its handling process as a working process, then the loader scheduling can be understood as a kind of special department scheduling job. The department scheduling problem (Job-Shop Scheduling Problem,

referred to as JSSP) can be expressed as: have n- kinds of wood $\left\{J_{1}, J_{2}, J_{3}, \mathrm{~L}, J_{m}\right\}$ to be processed in m-machines $\left\{M_{1}, M_{2}, M_{3}, \mathrm{~L}, M_{m}\right\}$, each kind of wood contains a process composed of multi-channel collection $\left\{O_{i j}\right\}$, which $O_{i j}$ indicates that the $j$ process of the $i$ wood industry, wood processing order is given in advance, processing time of each process may fluctuate, but the average available, in addition to the machine and wood have some basic constraints, such as: each machine only have once wood processing; the process begins, it can not be interrupted; after the permit for timber processing on other machines, it can be return to the original machine and so on.

The problem to be solved in the job scheduling is to determine the processing sequence of each machine (loader and other shared machines), allocate the resources reasonably, and make the scheduling result meet the preset schedule.

For non-deterministic problem of complete polynomial can be solved by exhaustive method. Because of the complexity of the algorithm and the amount of input data is exponential relationship, so the calculation of the time with the complexity of the problem of exponential growth, and ultimately will not be able to calculated .

Verify the feasibility of a loader job scheduling, which is a P problem. The P problem is a decision problem that can be solved in polynomial time(A decision problem is a question that needs to be answered "yes" or "no" ). But if it is the best solution to the job scheduling, it is a NP-Hard problem (NP problem). The NP problem is the problem that the "guess" result can be verified in polynomial time.

\subsection{Loading-Machine Scheduling Objectives}

The goal of the loader job scheduling is:

(1).Instructions deliver necessary loader $\log$ when necessary (chip) to the position. Therefore, to select the appropriate instructions to send in time, the appropriate allocation of resources.

(2).Executable job only. That is to say, the loader has the right to execute the first job instruction and does not have the right to choose which job to perform.

(3).The loader movement target position calculation (location calculation) to achieve the comprehensive optimal storage strategy. The calculation results to the exact location, only, and not to crash phenomenon.

(4).The total operating time is the shortest, or that all the work should be taken into account in advance to the production of the work out of the shortest distance between the carrier motion.

(5).Personnel and equipment utilization is the largest, the average delay time is the shortest, and the waiting time is the shortest.

(6).The scheduling system is easy to operate, easy to accept and understand.

\section{Production Scheduling Problem Model and Improvement of Loader}

\subsection{Disjunctive Graph Model}

Based on the mathematical model of the disjunctive graph model of loader scheduling problem in the analysis of the available graph represented. Disjunctive graph proposed by Roy and Sussman in 1964, after the Job Shop scheduling problem instance description has been widely studied and applied. Disjunctive graph $W$ $(M, B, H)$ is defined as follows: $\mathrm{M}$ is the vertex set, set corresponding to all processes (including two virtual procedure, respectively, the beginning and the end); B is a directed edge set, said sequence constraints of each process with a wood between the lines in the figure represented by one-way; $\mathrm{H}$ is a disjunctive edge the collection, it is an undirected edge set, said mutex relationship is processed in the same machine process, with a dotted line in the figure. Disjunctive edge set is divided into sub set $H \quad H_{1} \mathrm{U} H_{2} \mathrm{UL} H_{k}$, which $H_{k}$ indicates that the $\mathrm{K}$ machine procedures set. In-out warehouse operation scheduling problem disjunctive as shown in Figure 1.

Figure 1 have 3 parts, multiple machines disjunctive graph examples, the machines here include: loading machine, electronic weighing (virtual machine), log chain feeder, peeling machine. The logs andpurchased wood chip processing includes 4 steps (production library, electronic weighing, input, processing), net tablet contains 4 
procedures (cross line library, feeding, input, processing), node corresponding process set, where o and*is the starting process and dummy and termination processFigure 1 have 3 parts, multiple machines disjunctive graph examples, the machines here include: loading machine, electronic weighing (virtual machine), log chain feeder, peeling machine. The logs and purchased wood chip processing includes 4 steps (production library, electronic weighing, input, processing), net tablet contains 4 procedures (cross line library, feeding, input, processing), node corresponding process set, where $\mathrm{o}$ and ${ }^{*}$ is the starting process and dummy andtermination process $\mathrm{N}=\{\mathrm{O}$, $\left.\mathrm{O}_{11}, \mathrm{O}_{12}, \mathrm{O}_{13}, \mathrm{O}_{14}, \mathrm{O}_{21}, \mathrm{O}_{22}, \mathrm{O}_{23}, \mathrm{O}_{24}, \mathrm{O}_{31}, \mathrm{O}_{32}, \mathrm{O}_{33}, \mathrm{O}_{34}, *\right\}$.The set of connected edges $\mathrm{A}=\left\{\left(\mathrm{O}_{11}, \mathrm{O}_{12}\right),\left(\mathrm{O}_{12}\right.\right.$, $\left.\left.\mathrm{O}_{13}\right),\left(\mathrm{O}_{13}, \mathrm{O}_{14}\right),\left(\mathrm{O}_{21}, \mathrm{O}_{22}\right),\left(\mathrm{O}_{22}, \mathrm{O}_{23}\right),\left(\mathrm{O}_{23}, \mathrm{O}_{24}\right),\left(\mathrm{O}_{31}, \mathrm{O}_{32}\right),\left(\mathrm{O}_{32}, \mathrm{O}_{33}\right),\left(\mathrm{O}_{33}, \mathrm{O}_{34}\right)\right\}$ is the constraint of the process of each part. The hanging of non connected edge sets $\mathrm{E}_{1}=\left\{\left(\mathrm{O}_{11}, \mathrm{O}_{13}\right),\left(\mathrm{O}_{11}, \mathrm{O}_{21}\right),\left(\mathrm{O}_{11}, \mathrm{O}_{23}\right),\left(\mathrm{O}_{11}, \mathrm{O}_{34}\right)\right.$, $\left.\left.\left(\mathrm{O}_{13}, \mathrm{O}_{21}\right),\left(\mathrm{O}_{13}, \mathrm{O}_{23}\right),\left(\mathrm{O}_{13}, \mathrm{O}_{34}\right),\left(\mathrm{O}_{21}, \mathrm{O}_{23}\right),\left(\mathrm{O}_{21}, \mathrm{O}_{34}\right)\right),\left(\mathrm{O}_{23}, \mathrm{O}_{34}\right)\right\}$ corresponding to loader 1.

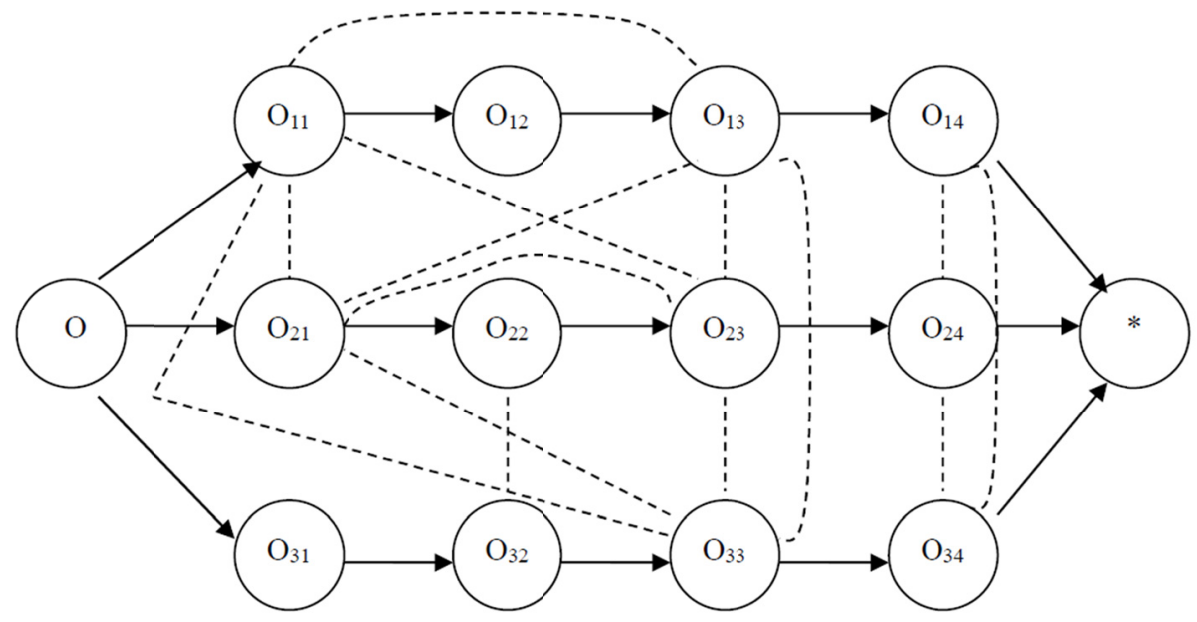

Figure 1. In-out warehouse operation scheduling problem disjunctive figure

\subsection{The Improved Disjunctive Graph Model}

The improved disjunctive graph $\mathrm{W}(\mathrm{M}, \mathrm{B}, \mathrm{R}, \mathrm{H})$ definition: $\mathrm{M}$ is the vertex set, set corresponding to all processes (including two virtual procedure, respectively, the beginning and the end); B is a directed edge set, said sequence constraints of each process with a workpiece, represented by one-way lines if the former process needs multiple machines, and after the process of sharing the same machine, there is from the procedure to every process resource sharing dependencies, represented by the solid line in the figure two; $\mathrm{R}$ describes the use of multi machine resource process different workpiece ordering processes to release the resource related constraints, represented by the solid line in figure 2 ; $\mathrm{H}$ is a disjunctive edge set, said mutex relationship is processed in the same machine process, represented by the dotted line in the figure of one-way, disjunctive edge set is divided into sub set $H=H_{1} \mathrm{U} H_{2} \mathrm{UL} H_{k}$, where $H_{k}$ said article on $\mathrm{K}$ machines. Process set. Figure 2 :The improved disjunctive graph examples.

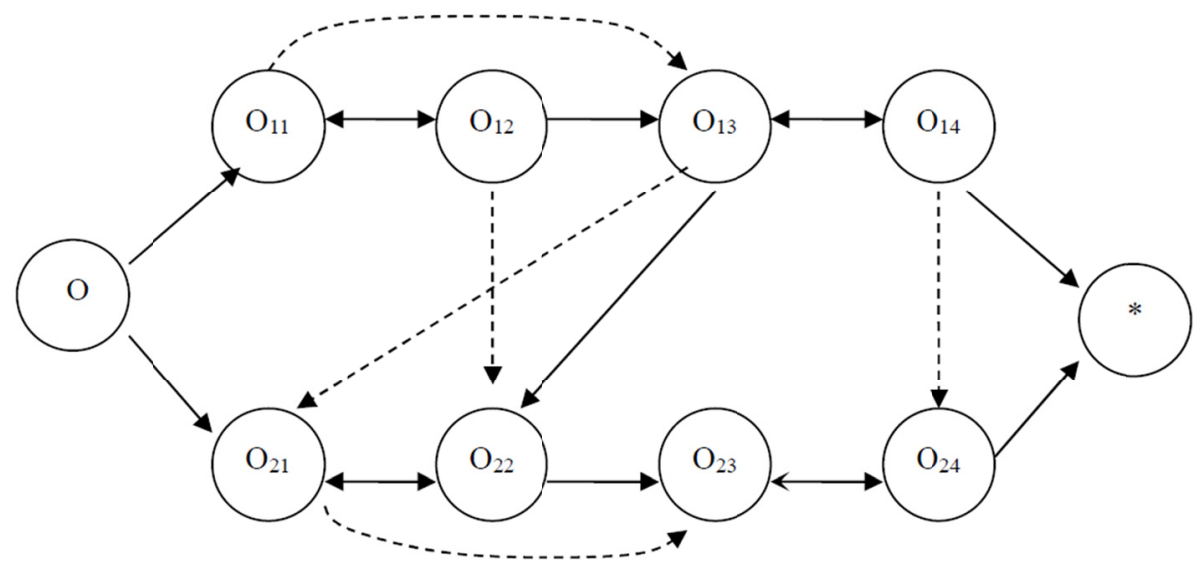

Figure 2. The improved disjunctive graph examples 


\section{Loader Intelligent Scheduling Algorithm}

This paper focus on the application of expert knowledge, seek a solution based on production scheduling algorithm with feedback mechanism, rule based reasoning and fast, it will not all one-time production plan of each parts list optimized combination, but purrent waiting for each job step out optimization solution, that is to say the former after the procedure and procedure for isolation, without making scheduling procedure to the former case, after the process of scheduling is meaningless, a waste of energy, once before the completion of the process, it will remove the former procedure, after the procedure will be included in, according to the load of machine resources the production scheduling. The feature of the algorithm is: (1) KBE (Knowledge Based Engineering, the application of Knowledge Engineering); (2) according to the resources of the computer load, only the necessary production scheduling; (3) scheduling is not completed by one time, a process is completed, will be solved again, calculate the optimal scheduling under the current situation; (4) scheduling system is a closed-loop control system with feedback mechanism, according to the current production status and automatic adjustment of the scheduling results. Figure 3 Based on rule reasoning homework scheduling solution model .

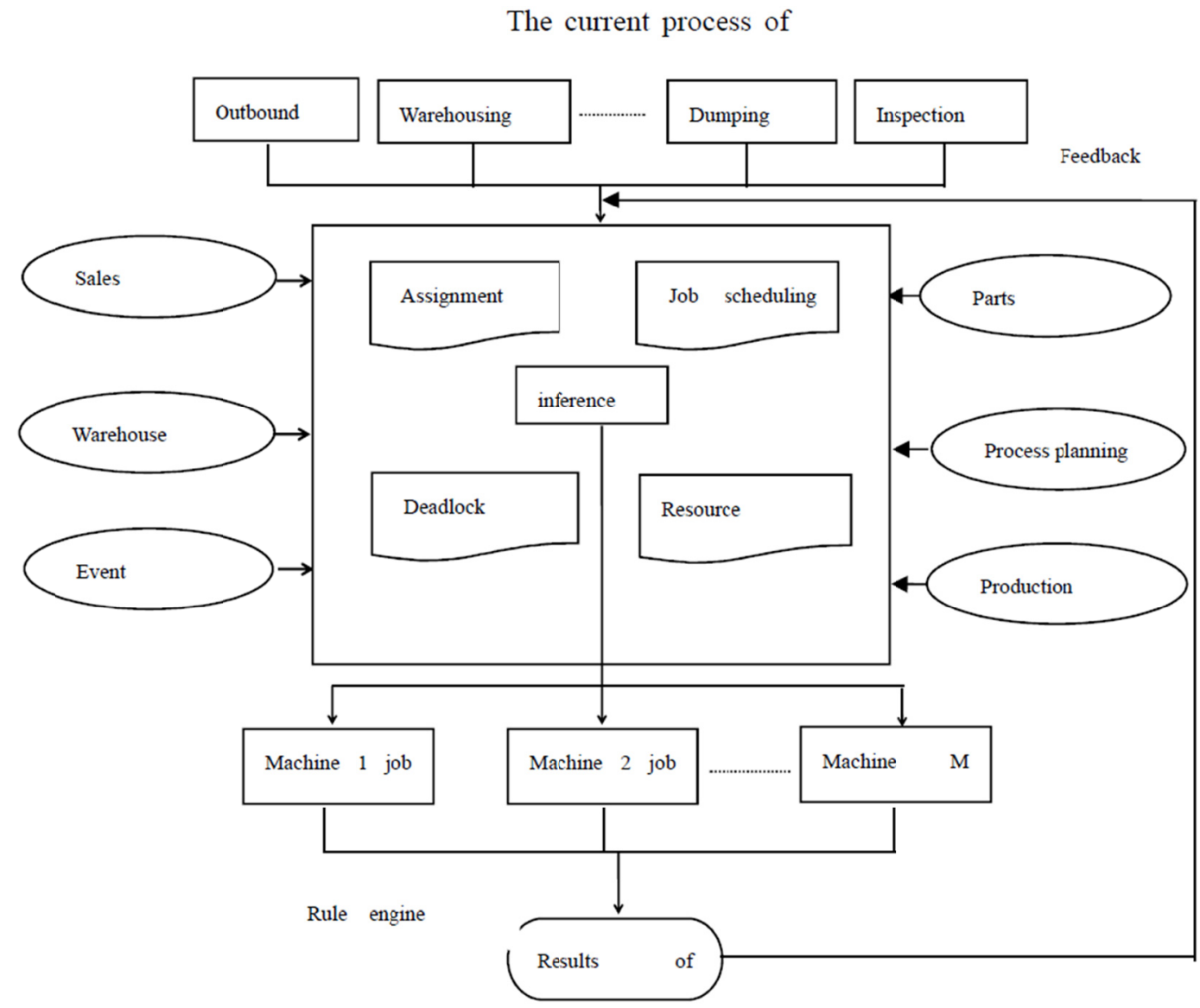

Figure 3. Based on rule reasoning homework scheduling solution model

\section{Computer Programming of Loader Production Scheduling}

In this paper, the production of a variety of loaders in the production of "outbound production" as an example to illustrate the loader production scheduling computer programming process.

Production line L1 has a loader, and a number of production out of place. Of course, if there are $\mathrm{N}$ jobs need to "produce a library", then repeat the process $\mathrm{N}$ times. First of all, to determine whether the "production output" production, if so, according to the actual log position inverse Library in the actual production line, if not the production line in L1, but the L2 production line, so it is necessary to give to another loader L2 issued "across the line " production, make the loader L2 put the wood transported to the target. Of course, according to the above-mentioned rules to solve the "cross the line" production in the production of L2 in the queue seating. This cross line library production is generated, and then solve the L1 loader production from the production, first of all to the "L1" production output production "to" stealth ", because L2" across the line from "production is not 
executed, if at this time to L1 loader released" production output production ", will cause the L1 loader" idle "and blocked the other normal production execution. Remove the L1 loader production queue from the hash table, according to the priority queue to queue in the production of production. This is only to modify the memory of the data, followed by synchronous modification of the database, the production queue will be stored in the database for permanent storage. The computer opened a special piece of memory to store the loader production queue, because the production queue often visit, and often to do the sorting process, if each treatment is to access the database, then slower processing speed and greatly increased the database load unnecessary. But put into memory, it is necessary to ensure the synchronization of memory data and database data, the requirements of synchronization processing technology is relatively high. At this point, "production output" production is created, but the electronic Display loader L1 on may long time do not appear in this production, this is because the system using "resource dependence" rules, automatically determine the production can be implemented, only when the "library" of resources, it will be displayed in the production indicator board.

\section{Conclusion}

Through the study of forest-pulp-paper enterprise Loading-Machine Production Scheduling Algorithm, we can analysis the Loading-Machine scheduling model of problems and improvement measures, and use Loading-Machine intelligent production scheduling algorithm, realize the Loading-Machine intelligent production scheduling through the computer programming.

\section{References}

David, A., \& Hensher, S. U. P. (2010). Refocusing the Modelling Of Freight Distribution: Development Of an Economic-Based Framework to Evaluate Supply Chain Behaviour in Response to Congestion Charging Transportation. Springer Science \& Business Media B. V., 32(6), 573-602

Jayalakshmi, S., Rajagopalan, S. P. (2007). Modular simulated annealing in classical job shop scheduling[J]. Information Technology Journa 1, 6(2), 222-226.

McCullen, P, \&Towill, D. (2009). Diagnosis and reduction of bullwhip in supply chains[J]. Supply Chain Management: An International Journal, 7(3), 164-179.

\section{Copyrights}

Copyright for this article is retained by the author(s), with first publication rights granted to the journal.

This is an open-access article distributed under the terms and conditions of the Creative Commons Attribution license (http://creativecommons.org/licenses/by/4.0/). 